\title{
Médiévales
}

Langues, Textes, Histoire

62 | printemps 2012

Hagiographie et réforme dans l'Occident latin

\section{Vincent Corriol, Les Serfs de Saint-Claude. Étude sur la condition servile au Moyen Âge}

Rennes, Presses Universitaires de Rennes, 2009, 400 p. (coll. Histoire)

David Glomot

\section{OpenEdition}

\section{Journals}

Édition électronique

URL : https://journals.openedition.org/medievales/6699

DOI : 10.4000/medievales.6699

ISSN : 1777-5892

\section{Éditeur}

Presses universitaires de Vincennes

Édition imprimée

Date de publication : 2 juin 2012

Pagination : 191-194

ISBN : 978-2-84292-346-4

ISSN : 0751-2708

Référence électronique

David Glomot, «Vincent Corriol, Les Serfs de Saint-Claude. Étude sur la condition servile au Moyen Âge », Médiévales [En ligne], 62 I printemps 2012, mis en ligne le 29 juin 2012, consulté le 24 avril 2022. URL http://journals.openedition.org/medievales/6699 ; DOI : https://doi.org/10.4000/medievales.6699

Ce document a été généré automatiquement le 24 avril 2022.

Tous droits réservés 


\section{Vincent Corriol, Les Serfs de Saint- Claude. Étude sur la condition servile au Moyen Âge}

Rennes, Presses Universitaires de Rennes, 2009, 400 p. (coll. Histoire)

\section{David Glomot}

1 La thèse de Vincent Corriol porte sur un des concepts essentiels de cette création de l'esprit qu'on nomme, au Moyen Âge, le servage. Ce qui n'est qu'une définition pour le juriste s'avère une réalité complexe et insaisissable pour l'historien : voilà qui méritait une enquête ciblée, ce qui est chose faite avec le cas très édifiant de l'abbaye jurassienne de Saint-Claude. L'auteur procède avec méticulosité et sur le long terme, du cœur du Moyen Âge jusqu'aux procès de la mainmorte, lors des Lumières. De fait, il utilise des sources longtemps inaccessibles, et habilement questionnées, en s'interrogeant sur la nature même du servage, sur ce qui fait le serf, à savoir les prestations dues à l'abbaye.

2 La taille puis la mainmorte font le serf, et c'est par ces outils de péjoration de la condition juridique, sociale et économique que les abbés assoient leur pouvoir sur la terre et les hommes, en jouant d'un large panel de stratégies pour renforcer une emprise à la fois qualitative et quantitative. Dans ces hautes terres du Jura, on est loin des présupposés classiques sur le second servage, lié aux crises de la fin du Moyen Âge, et porté par des seigneurs financièrement fragilisés et crispés sur leurs prérogatives. L'auteur fait remarquer que la chronologie et les modalités d'application de ce nouveau servage dérogent largement aux constructions historiographiques que l'on croit acquises. La servitude se bâtit sur un système complexe de relations et d'interactions, difficile à démêler. D'ailleurs, la principale source sur le servage reste l'affranchissement, qui nous renseigne par la négative et nous invite à un va-et-vient constant entre deux états, la soumission et l'émancipation, aux frontières finalement assez poreuses. Symptôme de cette complexité, le spectre sémantique large (55 termes), utilisé du $\mathrm{XIV}^{\mathrm{e}}$ au XVIII ${ }^{\mathrm{e}}$ siècle pour qualifier la «serve condition», invite à la relativisation et à une approche plurielle, que l'auteur parvient à mener avec brio. 
3 Sur les terres de l'abbaye de Saint-Claude, le servage est médiatisé de longue date, grâce aux diatribes de Voltaire, qui fit du serf jurassien l'incarnation archétypale de ce que les Lumières proscrivaient et combattaient. Grande seigneurie franc-comtoise, Saint-Claude offre un passionnant laboratoire d'étude pour percevoir autant les origines que les évolutions et la réalité quotidienne d'un statut complexe. La première partie du livre dresse ainsi un cadre de réflexion générale sur la question de la servitude et le durcissement des conditions.

4 Le servage résume à lui seul les relations sociales médiévales, par sa présence ou son absence, son intensité et sa complexité. À Saint-Claude, l'abbé affermit son pouvoir et réorganise le temporel de la communauté au cours du XIII ${ }^{e}$ siècle, et l'on voit apparaître officiellement le servage dans les textes en 1289 : ce n'est pas alors un phénomène neuf, mais un fait déjà acquis. Le début du XIV siècle correspond à une vive phase de mise en valeur des hautes terres, l'émergence du servage favorisant le processus, au profit de l'abbé. C'est vers 1300 qu'est rédigé un Livre d'or, état des lieux foncier et seigneurial, énumérant 122 églises et de nombreux hommages. Ce censier-rentier, fruit d'une complexe campagne de collecte, vise à recenser des droits, pour mieux les garantir et les cristalliser ou, du moins, pour donner l'impression d'un domaine bien tenu. Le temporel de Saint-Claude est alors aux mains de prévôts, des laïcs chargés par l'abbé de prélever des redevances par foyers (la taille), des redevances sur la terre (par meix/ mansum), et des droits seigneuriaux, comme les banalités. Cette profusion d'obligations permet de mettre en évidence les structures sociales et de distinguer par la fiscalité le franc du serf, aussi appelé taillable.

5 La seconde partie du livre montre la formation et l'extension du statut servile, puisque les francs « disparaissent de l'horizon social » au XIve siècle (p. 117), pour laisser la place à une nouvelle norme, faite de soumission. Si, jusque vers 1350, c'est la taille qui fait le serf, la mainmorte entre en jeu par la suite, et permet de verrouiller les héritages, et donc les conditions. À la fin du XIV siècle, après un lent glissement, le lien juridique est considéré comme acquis, entre la taillabilité et la restriction successorale : "taillable » et «mainmortable» deviennent synonymes, un principe parmi d'autres finissant par résumer à lui seul le statut servile qui, vers 1420 , est clair, incontesté, tout comme celui du bourgeois, à l'extrême opposé du spectre social. Cette forte polarisation, qui ne laisse presque plus d'espace pour les francs, s'accompagne d'un essor du droit écrit et de la pratique notariale, au service du seigneur abbé.

6 La crise du bas Moyen Âge a certainement facilité cette radicalisation, initiée dès le $\mathrm{XIII}{ }^{\mathrm{e}}$ siècle : pour réoccuper les terres vacantes et fixer les hommes, les abbés manient autant la perpétuité de la tenure, sécurisante, que la mainmorte, restrictive. Un tel phénomène n'est pas nouveau et trouve des échos dans d'autres provinces aux capacités agraires tout aussi moyennes, comme l'Auvergne, le Bourbonnais ou la Marche.

7 Les populations ont-elles échafaudé des stratégies de contournement ou d'atténuation, pour contrecarrer les volontés de l'abbé ? La formation de communautés villageoises peut être vue comme une réponse. Néanmoins, au $\mathrm{xv}^{\mathrm{e}}$ siècle, on a l'impression que le servage est accepté placidement et fait l'objet d'une pratique quotidienne résignée, sans révolte ni contestations, à l'inverse de ce que l'on constate en Allemagne, GrandeBretagne et Catalogne. On attendra les Lumières pour élever la voix contre les pratiques sanclaudiennes. 
Constate-t-on alors des formes de résistance douce ? Les migrations vers la ville ou des seigneuries voisines plus souples, que l'on appellerait déguerpissements ou désertions, sont très rares, preuve d'une acceptation généralisée d'un fait devenu coutumier. Il est vrai que le glissement vers le servage n'a pas été brutal et qu'à Saint-Claude règne le principe du cas par cas, de l'exception négociée et de la modulation généralisée. Un procès de 1475 (p. 290) montre tout le flou et les paradoxes qui accompagnent le statut de mainmortable : des témoins interrogés disent « ne rien savoir » sur la mainmorte, ne rien pouvoir en dire, alors qu'ils y sont soumis de façon héréditaire.

9 À une échelle encore plus locale que la communauté villageoise, la communauté familiale sert d'amortisseur et d'ultime stratégie d'évitement. Selon les lieux et les époques, ces regroupements de parents dans le même foyer représentent entre un quart et un tiers des aveux, ce qui reste modeste comparé à ce qui est constaté dans d'autres régions. Néanmoins, dans le Jura comme dans les autres terres de mainmorte, les communautés familiales sont nettement mieux représentées dans les zones de soumission forte, alors que la famille nucléaire est la norme dans les zones émancipées.

La dernière partie du travail de Vincent Corriol invite ainsi à découvrir la servitude au quotidien, dans sa pratique routinière, sinon acceptée. À partir de 1440, l'étude des affranchissements individuels et collectifs concédés par l'abbé révèle ainsi des espaces de liberté et des espaces de soumission, autant de contrastes qui permettent de mieux décrire la réalité de la vie des mainmortables. $\mathrm{Si}$, à l'origine, la taille, taxe foncière réelle, faisait le serf, c'est désormais la mainmorte, contrainte personnelle, qui définit le mieux le statut de la majorité des paysans. À cause de cette obligation première, tout un complexe servile se met en place, contraignant les hommes à fournir des corvées, " œuvres ", «journées", «réparations» et autres "charrois». Deuxième forme de péjoration, les incapacités rappellent le statut inférieur du serf, qui ne peut témoigner, tester, disposer de ses biens, avoir le droit de bourgeoisie, choisir sa résidence, entrer dans les ordres... Capable de peu et obligé à beaucoup, tel est le serf; mais des possibilités d'ascension sociale existent. La norme foncière tourne autour des dix hectares par ménage, avec deux tiers de terres arables et un tiers de prés, mais cette moyenne cache des disparités. Certaines familles serves sont riches ou le deviennent, et l'achat d'un affranchissement est donc envisageable. Cet acte est le préalable à une installation en ville et à l'acquisition du droit de bourgeoisie.

On regrettera, en fin de compte, que ce livre soit peut-être trop court, par la faute des contraintes éditoriales, et trop pauvre en cartes et figures, mais le lecteur ressort de ces 400 pages avec une vision limpide et neuve de ce qu'est le servage, du moins dans une de ses traductions locales. Vincent Corriol présente un phénomène à la fois conforme à l'idée que l'on s'en fait et paradoxalement très exotique, loin des normes colportées par des générations d'auteurs. On touche ici à de vraies pratiques, de vrais faits, ce qui donne une saveur nouvelle à une problématique loin d'être épuisée. 